\title{
Using social sustainability principles to analyse activities of the extraction lifecycle phase: Learnings from designing support for concept selection
}

\author{
Rachael Gould*, Merlina Missimer and Patricia Lagun Mesquita
}

\author{
DePARTMENT OF StRATEGIC SUSTAINABLE DEVELOPMENT, \\ BLEKINGE INSTITUTE OF TECHNOLOGY
}

*Corresponding author: rachael.gould@bth.se

\begin{abstract}
Analysing product concepts with respect to social sustainability is a contemporary challenge for which there is little support available for product developers. Our aim was to build on previous work to support product developers in a case company with this challenge. Previously a definition of social sustainability was developed from science on how the social system functions. We designed a first prototype of support for product developers to use this previously developed definition when analysing the extraction lifecycle activities associated with their product concepts. The prototype instructs users to model the location of the extraction activities and then use existing databases and indicators to analyse the social sustainability performance of each location. The databases and indicators were selected according to their relevance to scientific principles for social sustainability. We then performed initial evaluation of the support, through which we learnt that the approach may make it possible for product developers to analyse extraction activities, but the level of accuracy of analysis that is possible is not good enough for comparing the concepts in the case study decision. We discuss the implications of these challenges and suggest that it may be better to re-design our approach in order to provide learningful support for product developers or support for other decisionmaking in the company.
\end{abstract}

\section{INTRODUCTION: THE NEED FOR SUPPORT}

Sustainable product development is a young and rapidly developing field. However, much of the work has focused on reducing negative environmental impacts, while the social dimension has been less well-covered (Gmelin and Seuring 2014). Socially sustainable product development is the processes and practices that lead to products whose lifecycles have a less negative impact on the social system. The weak coverage of socially sustainable product development mirrors the general sustainable development field, where the social dimension of sustainability has essentially been overlooked (Littig and Griessler 2005, Partridge 2005, Kunz 2006, Cuthill 2010, Dempsey et al. 2011, Vallance et al. 2011) 
and has been found to be lacking a clear theoretical concept (Littig and Griessler 2005, Dempsey et al. 2011), a clear understanding of the meaning and interpretation of social sustainability (Weingaertner and Moberg 2014) and clear indicators that help distinguish socially sustainable development from socially un-sustainable development (Omann and Spangenberg 2002). Attempting to address these gaps, in previous work, one of the authors derived the following principles that together form a definition of social sustainability from the science of social systems (Missimer et al. in this issue a \& b).

In a socially sustainable society, people are not subject to structural obstacles to ...

1....health.

2. ...influence.

3. ...competence.

4. ...impartiality.

5....meaning-making.

Structural obstacles refer to social constructions - political, economic and cultural which are firmly established in society and upheld by those with power. Due to various kinds of dependencies and other factors, such obstacles are difficult or impossible to overcome or avoid for those affected by them.

The newly derived definition of social sustainability (known as the social sustainability principles) is part of a Framework for Strategic Sustainable Development (Missimer et al. in this issue a \& b). This framework, including a definition of environmental sustainability and an earlier definition of social sustainability, has been used for over two decades and in a variety of contexts (Broman and Robèrt 2015). The social sustainability principles have been used with preliminary results in strategic planning (for example, Missimer et al. 2014), but have not yet been rigorously developed and tested in the product development and concept selection decision realm. Others have worked with applying the previous definition of social sustainability from the framework for strategic sustainable development in the product development domain. Examples include Ny et al.'s (2006) approach for strategic lifecycle management, Byggeth et al.'s (2007) method for sustainable product development and Hallstedt's (this issue) sustainability criteria.

This paper covers a case where product developers were interested in understanding how they themselves could analyse product concepts with respect to social sustainability. They ultimately wanted to use this analysis to inform their concept selection decision-making. Selecting concepts occurs in the early phases of product development (Krishnan and Ulrich 2001), when design freedom is high (Ullman 2003) and when there is greater potential to reduce negative sustainability impacts (Bhamra et al. 1999). A product concept is an idea of a technical solution and associated features, working principles, attributes and customer benefits (Ulrich and Eppinger 2012). Selecting concepts involves making trade-offs between various attributes of the concepts (Ulrich and Eppinger 2012), for example, trading between initial cost, long-term brand image, functional performance and usage cost. The product developers in the case company wanted to analyse two aerospace engine components in order to understand and compare the social sustainability attributes of these concepts.

The case company were already starting to use the framework for strategic sustainable development (for example, Hallstedt in this issue, Hallstedt and Isaksson 2013) and now they wanted to use it for 
this specific decision - concept selection ${ }^{1}$. Early in the development process is also when product developers may experience time-pressure. This time pressure is not a surprising result of the race for shortest time-to-market. The case company were therefore interested in time-efficient ways of using the social sustainability principles to analyse product concepts.

A much discussed collection of approaches for analysing products with respect to social sustainability, but that is not based on the principles, is Social lifecycle assessment (SLCA). Challenges with SLCA are well captured in the literature (for example, Jørgensen et al. 2008; Benoît et al. 2010; Dreyer et al. 2010; Wu et al. 2014). A particular challenge for this case was that SLCA methodologies are used by SLCA researchers or experts and take a long time for even the experts to employ. Since the product developers in this case do not have either the time or the expertise to apply SLCA and therefore SLCA was not appropriate for this study. The SLCA is also not based on the newly developed social sustainability principles that we and the case company wanted to apply.

Since existing support does not test the use of the newly developed social sustainability principles and, in some cases, does not address the needs of the time-pressed product developers at the case company to analyse their concepts, a knowledge gap remains. The research question that guided our study was:

How might product developers at the case company use the social sustainability principles to analyse product concepts with respect to social sustainability?

To address this question, we developed a prototype of support and evaluated it in the case study context. Specifically, the product developers wanted to analyse two aerospace engine components, and they expressed a preference to do this numerically. In addition, we focused specifically on support for analysing the extraction phase of the lifecycles of these two components. Our goal was to develop an early version of time-efficient usable support that the case product developers could employ and test. We had anticipated that product developers could employ existing indicators and databases, but we found that was not the case. Our intent with this paper is to share the learning that we gained through pursuing this goal in order to address the above research question.

${ }^{1}$ Note that the case is not about re-designing concepts or other aspects, but focused specifically on the decision where they select between existing concepts. 


\section{RESEARCH APPROACH}

This work is part of a set of studies that aim to support people and organisations to act in a more socially sustainable way, with a subset focused on supporting socially sustainable product development practice. These studies are together framed by design research methodology. Blessing and Chakrabarti's (2009) design research methodology comprises studies for (1) clarifying the research focus, (2) understanding the need and context, (3) developing support, and (4) evaluating the support and suggesting improvements. In the study captured in this paper, we build on earlier work on the understanding of social sustainability (see Missimer et al. in this issue a $\&$ b) and of the case company context (see Bertoni et al. 2014; Hallstedt and Isaksson 2013; Thompson et al. 2011). This study corresponds to the third and fourth studies of the methodology. In particular, we developed and evaluated a prototype of support for product developers to use the social sustainability principles to analyse product concepts.

In order to develop and evaluate support, we employed a prototyping approach. In line with a prototyping approach (Kelley 2001), we iterated between designing and testing in order to learn quickly and early, and then to incorporate these learnings in the next design task. As we iterated, we reflected on what we were doing, how well it was working and whether it seemed like it would be relevant and usable by product developers in the given context.

For the testing, we used the prototype on an example case, which, according to Savin-Baden \& Major (2013) and Yin (2009) enables more realistic evaluation As an example decision, the case company provided a past selection decision between two concepts that differ only in material (and consequential attributes, such as thickness and manufacturing processes). In this paper, these concepts are referred to as concept $A$ and concept $B$.

Testing was performed through two main activities. Firstly, as part of prototyping, researchers played the role of product developers and used the prototypes of support to analyse the extraction phase lifecycle activities of the two concepts. In line with Blessing and Chakrabarti (2009), this enables researchers to gain initial learnings about potential and issues without using actual product developers' time for testing it. Secondly, we shared our results and experiences with the case company representatives and gathered feedback. The feedback was gathered from two groups. The first group consisted of three company representatives who are members of the research project of which this study is part. The second group was six individuals from various backgrounds related to concept development and associated decisions within the company.

Although the research process involved many iterations and was therefore not linear, the results are described in a straightforward manner in the next sections. Section 3 describes the prototype - an approach comprising of multiple steps - while section 4 focuses on the application to the specific case. Section 5 then covers the evaluation results, while section 6 offers some discussion on the overall findings.

\section{THE SUPPORT}

As per the prescriptive study of design research methodology (Blessing and Chakrabarti 2009), we combined state of the art literature from relevant disciplines to design the support. In subsection 3.1, we outline the prototype - an approach for analysing the extraction phase lifecycle activities - and then explain the design decisions in the following subsections. 


\subsection{OVERVIEW OF THE APPROACH}

A main challenge in analysing early supply chain activities, including extracting and processing raw material, is that product developers generally know very little about how these activities are performed. For example, companies tend not to know where the particular molecules that they use were extracted, by whom and under what social conditions. We therefore sought ways to model the system in order to achieve approximates for the results.

In order to approximate the analysis of the activity 'extracting raw materials', we suggest that product developers first identify the raw materials that are extracted and then identify the likely locations where these materials were extracted. The product developers then have a model of locations of extraction, and so they can use a selection of social sustainability indicators to assess the countries in this model. This means that the support only leads to an estimate of the risk of being socially unsustainable because it is based on the probability that each mineral is extracted in each country and that the activities are being done with the level of social sustainability that matches the level reported for the country. However, given the current state of affairs, this might be the product developers' best chance.

The prototype of support therefore comprises the following steps.

1. Identify minerals used in concepts.

2. Use the World Mineral Statistics dataset (Minerals UK 2014) or similar to identify the top producing countries that together produce $50 \%$ of the world's production of each mineral/ore, thus creating a model of likely extraction location.

3. Use the databases and indicators below to get a score for each country for each indicator.

- Health

- Social hotspots database:

- Wage Assessment

- Poverty

- Forced Labour

- Child Labour

- Working Time

- Occupation Injuries \&Deaths

- Occupation Injuries \& Hazards

- Access to Improved Drinking Water

- Access to Improved Sanitation

- Access to Hospital beds

- Human Health Noncommunicable diseases and other health risks

- Human Health Communicable diseases
- Impartiality

- Sustainable society index:

- Income distribution

- Social hotspots database:

- Migrant Workers

- Corruption

- Legal System

- Gender Equity

- Indigenous Rights

- Influence

- Social hotspots database:

- Freedom of Association, Collective Bargaining and Right to Strike

- Social progress index

- Freedom of speech

- Competence

- Social progress index

- Access to basic knowledge

- Access to info \& communications

- Years of tertiary schooling

- No. globally ranked universities

4. Perform analyses by calculating a score for each concept

- Sum the product of the indicators scores for each country with the percentage contribution of each country to $50 \%$ of the top producing countries. This gives element scores against each indicator. 
- Sum the product of the element scores with the percentage composition contribution for each element. This gives a score for each concept for each indicator.

- Weight the indicators relative to each other in order to give a total concept score for each principle.

- Sum the scores per principle (with equal weighting across the principles). This gives a score for the concept.

\subsection{STEP 2: MODELLING EXTRACTION LOCATION}

For the model, we used the World Mineral Statistics dataset (Minerals UK 2014) to identify the top producing countries for each mineral. We chose to use this dataset after searching for options and identifying this one as being comprehensive for the minerals we were interested in. Also, a number of other databases were based on this dataset. In particular, we identified the top producing countries that together produce $50 \%$ of the world's production of that mineral/ore. We looked in the data set for the producing countries, listed these countries in order of contribution to global production and then noted down those that contributed to the 'top' 50\%. We then scaled these top producers to give $\%$ of contribution to the $50 \%$ produced by top producing countries.

Some other supply risk indicators, such as the British Geological Survey's Risk List (British Geological Survey 2012), use only the top producing country (from the same data set). Since there is wide variation in how much the top producer actually produces - for example, from Canada being top producer of titanium minerals with $18 \%$ of global production to Brazil being top producer of tantalum and niobium minerals with $95 \%$ - this would cause a huge variation in the numerical representation of risk. We therefore considered it more reasonable to create a model by choosing a percentage and truncating contributions where appropriate so that we could use numerical operators without skewing the data. We chose the specific percentage of $50 \%$ because it seemed a large enough proportion without giving too many countries to analyse for each element.

\subsection{STEP 3: USING SOCIAL SUSTAINABILITY INDICATORS TO SCORE EACH COUNTRY}

Step 3 for the product developers is to use existing databases and indicators to get a score for each country. This means that we needed to identify relevant and useful databases and indicators that could be used by a time-pressed non-specialist. These indicators needed to help users apply the new social sustainability principles when analysing countries.

In our initial search for indicators of social sustainability for a country (or element), we identified the following list. Some of these are connected, using data or indicators from each other.

- Social hotspots database (SHDB)

- Social progress index (Social progress imperative 2014)

- Sustainable society index

- Human development index and Inequality-adjusted human development index (UNDP n.d.)

- Good country index

- World Bank's worldwide governance indicators

- British Geological Survey's risk list

We considered each of the above indicators for how they would help us analyse countries with respect to each social sustainability principle. The SHDB has several layers - a total score, categories, themes and indicators - and we mapped each theme against the sustainability principles in order to understand how well the database could help us with the required analyses. Under step 3 in section 
3.1, it is possible to see how we mapped the themes from the SHDB against the social sustainability principles. We also used experience from other projects (see Missimer 2015; pg 169-204) and knowledge of social issues to try to identify the gap between what the database covers and covering the 'whole' of the principle. For example, for impartiality, the indicators do not cover all forms of discrimination, nor income inequality.

Since the SHDB's indicators provided good coverage of the principles, and was designed to offer the information necessary to conduct a generic SLCA (Norris, Norris and Aulisio 2014), we used these indicators as base. The SHDB indicates social sustainability results for a given industrial sector in a given country. For example, we used 'ferrous metals' and 'metals' as the industrial sectors for each of the countries in the model.

We then focused on the gap between what is needed to cover all the principles and what the SHDB covers, and sought other indicators to see if they could fill in the gaps. The social progress index (Social Progress Imperative 2014) had the second broadest coverage of our needs, and so we next looked at whether it could fill in some of the gaps. We selected those indicators that were relevant in order to fill in the gaps. Note that, as appropriate, we used either a whole component (for example, 'access to basic knowledge') or selected indicators within a component (for example, 'years of tertiary schooling').

After selecting indicators from the SHDB and the social progress index, we still had a gap under the principle of impartiality. We needed an indicator to help us understand inequality of income in a given country. We identified two candidate indicators - the sustainable society index's (2012) indicator for income distribution and the human development index's (UNDP n.d.) indicator for inequality in income. The human development index's indicator had missing data for one of the countries that we needed and so we chose to use the sustainable society index's indicator. Note that we could not find a suitable indicator for meaning-making.

Now we had a set of indicators that we could use to help us understand the potential social conditions in the identified countries. However, during our testing, we found that it was hard work to navigate the SHDB and extract the values for each country at this level of detail. Therefore, we opted to also explore easier options and developed two more options, based on the first, in Table 1.

By using the total score from the SHDB, instead of individual themes, a user would cut down their work time significantly. However, using the total score means that the user cannot generate a score for each principle. In this option (option 2), the results are therefore displayed qualitatively and can only be summarised (in total) if they all point in the same direction. Another challenge with this option is that the theme 'high conflict zones' is automatically included, yet we had decided to exclude this theme when doing our mapping against the principles.

Although option 2 is designed to be easier to use than option 1, it has the disadvantage of the user not being able to generate a total score for the concept. We therefore also designed another option - option 3 - to be an easier version that provides a numerical sum. To do this, we simplified the mapping to use the SHDB against only impartiality and health. One disadvantage with this option is that we needed to drop the income distribution indicator. Another disadvantage is that the themes that were mapped to influence are now included under impartiality and health, due to the simplified mapping. So, although this option gives a numerical sum, it already has a number of inaccuracies in its design. In Table 1, we visualise the three options. 


\section{Option 1}

\begin{tabular}{|c|c|c|}
\hline \multirow{6}{*}{ 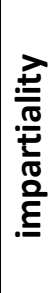 } & \multicolumn{2}{|c|}{ Income distribution } \\
\hline & \multirow{18}{*}{ 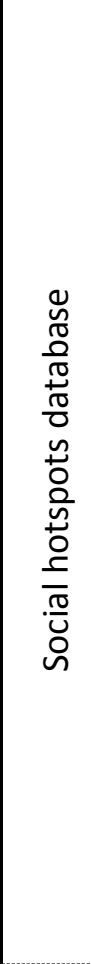 } & Migrant Workers \\
\hline & & Corruption \\
\hline & & Legal System \\
\hline & & Gender Equity \\
\hline & & Indigenous Rights \\
\hline \multirow{12}{*}{ 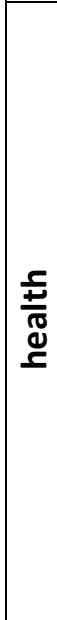 } & & Wage Assessment \\
\hline & & Poverty \\
\hline & & Forced Labour \\
\hline & & Child Labour \\
\hline & & Working Time \\
\hline & & Occupation Injuries \&Deaths \\
\hline & & Occupation Injuries \& Hazards \\
\hline & & Access to Improved Drinking Water \\
\hline & & Access to Improved Sanitation \\
\hline & & Access to Hospital beds \\
\hline & & $\begin{array}{l}\text { Human Health Non-communicable } \\
\text { diseases and other health risks }\end{array}$ \\
\hline & & $\begin{array}{l}\text { Human Health Communicable } \\
\text { diseases }\end{array}$ \\
\hline \multirow{6}{*}{ 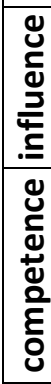 } & & $\begin{array}{l}\text { Freedom of Association, Collective } \\
\text { Bargaining and Right to Strike }\end{array}$ \\
\hline & \multirow{5}{*}{ 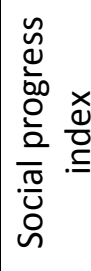 } & Freedom of speech \\
\hline & & Access to basic knowledge \\
\hline & & Access to info \& communications \\
\hline & & Years of tertiary schooling \\
\hline & & No. globally ranked universities \\
\hline \multicolumn{3}{|c|}{ neaning-making no indicators identified } \\
\hline & & TOTAL \\
\hline
\end{tabular}

Option 2

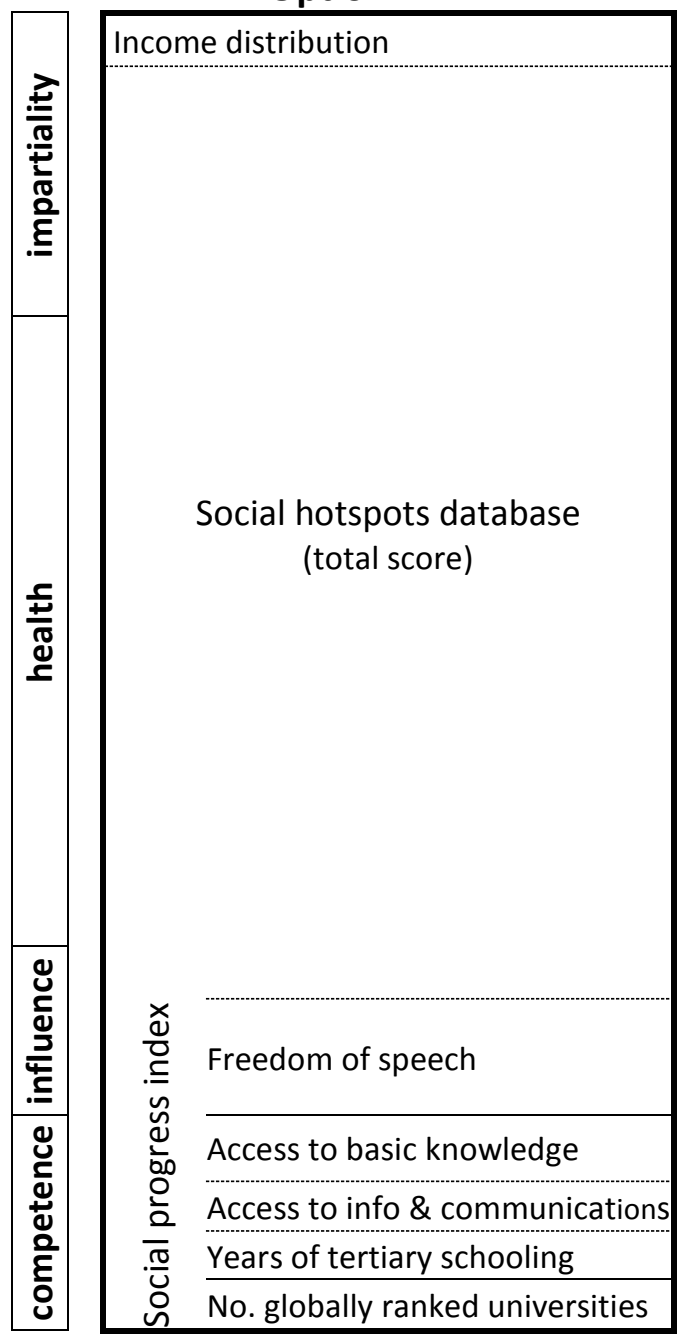

meaning-making no indicators identified
Option 3

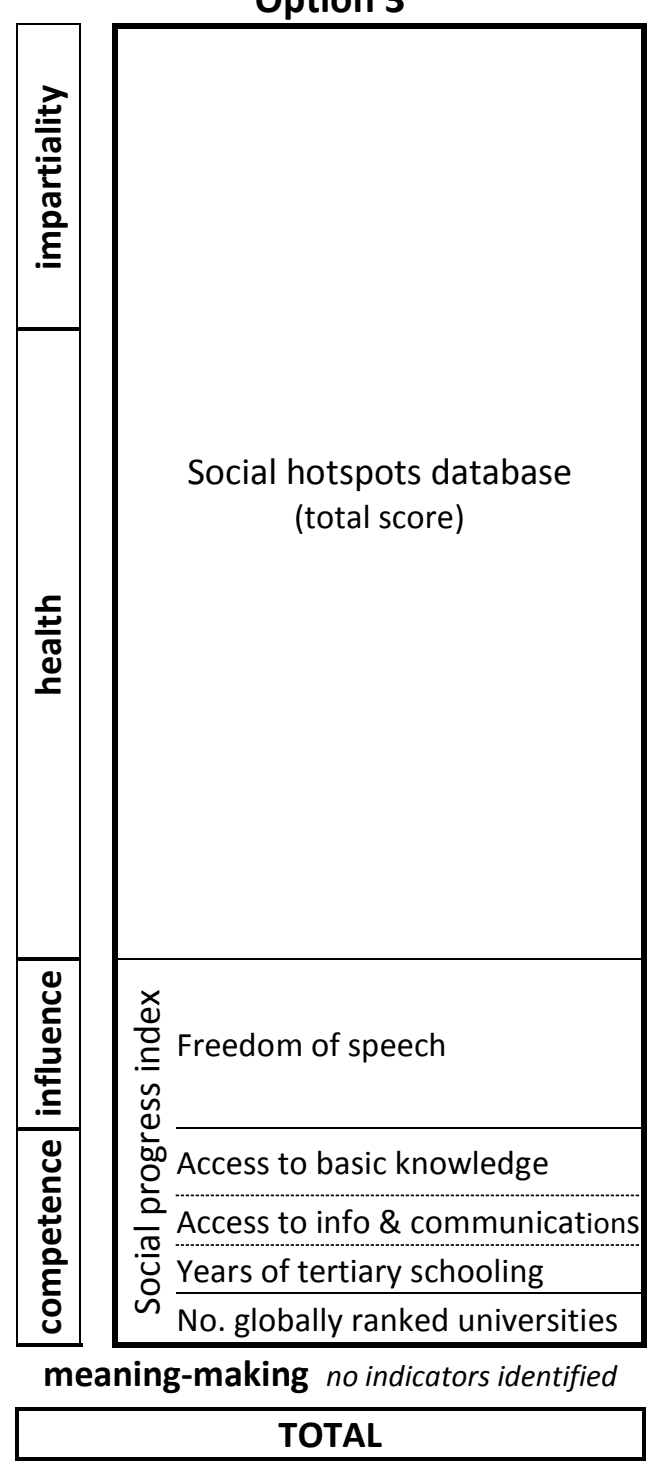




\subsection{Step 4: CALCULATING SCORE}

In order to be able to summarise a score for each indicator and a total score (for options 1 and 3), a product developer needs a way to total the individual indicators for each country to give a score for each alloy. For each element, we propose summing the product of the indicators scores for each country with the percentage contribution of each country to $50 \%$ of the top producing countries. And then, the product of the element scores with the percentage composition contribution for each element can be summed to give a score for the (extracting materials lifecycle activity for the) concept for that particular indicator, as outlined in Equation 1.

\section{Equation 1}

Concept score for a

given indicator

$$
\left.=\sum_{\text {elements }}^{\% \text { of element }} \begin{array}{c}
\text { in alloy } \\
\text { countries }
\end{array} \begin{array}{c}
\text { indicator score } \\
\text { for country } \\
\text { (as } \%)
\end{array} \cdot \begin{array}{c}
\text { country contribution } \\
\text { to top producing } 50 \%
\end{array}\right)
$$

The next step (for options 1 and 3 ) is to weight the indicators relative to each other in order to give a total concept score for each principle. Similarly, the principles need weighting relative to each other in order to sum across all principles. We propose weighting the principles equally since they are of equal importance for achieving a sustainable social system. We also decided to equally weight the indicators within each principle, and we did this at the indicator level rather than at the theme / component level.

Future versions of the prototype could include scaling for functional unit and percentage of material that is virgin or recycled.

\section{CASE STUDY TESTING}

As introduced in section 2, after designing the above 4-step approach, we tested applying it for the case study decision. Specifically, we performed the above four steps in order to analyse and compare the extraction activities associated with the two engine component concepts (concepts A and B).

\subsection{IDENTIFYING MINERALS}

We first identified the elements used in the two alloys being compared, including the percentage composition (using aksteel.com and suppliersonline.com). Similarly, we looked up in what form they are extracted. For example, aluminium is extracted as bauxite.

\subsection{MODELLING EXTRACTION COUNTRIES}

We executed step 2 to model the extraction location. Table 2 shows an example for bauxite. Australia, China and Brazil were the biggest producers of bauxite in 2012, contributing respectively $31 \%, 16 \%$ and $14 \%$ of global production (Minerals UK 2014). Together these add up to more than $50 \%$ and therefore Brazil's contribution is truncated before scaling to give a \%. Specifically, Australia and China's contributions add to give $47 \%$ and so only $3 \%$ of the $14 \%$ that is Brazil's contribution is needed to total $50 \%$. 


\begin{tabular}{lrrr}
\hline Country & $\begin{array}{c}\text { Metric tonnes } \\
\text { produced in 2012 } \\
\text { (Minerals UK 2014) }\end{array}$ & $\begin{array}{c}\text { \% of global production } \\
\text { in 2012 }\end{array}$ & $\begin{array}{c}\text { Contribution to 50\% of } \\
\text { top producing countries }\end{array}$ \\
\hline Australia & 76282000 & $31 \%$ & $61 \%$ \\
China & 40000000 & $16 \%$ & $32 \%$ \\
Brazil & 34955800 & $14 \%$ & $6 \%$ \\
\hline
\end{tabular}

\subsection{USING INDICATORS TO SCORE COUNTRIES}

In Table 3, we share an example calculation. The concept is made of steel 17-4PH, of which the main component is iron. The top producing countries are China and Australia, which produce $88 \%$ and $12 \%$, respectively, of the top $50 \%$. These two countries scored 4,2 and 4,4, respectively, on the indicator for income distribution (Sustainable society index 2012). The score for the element iron is therefore (the product of the two dashed rectangles in Table 3):

$$
\sum_{\text {countries }} \begin{gathered}
\begin{array}{c}
\text { indicator score } \\
\text { for country } \\
(\text { as } a \%)
\end{array} \\
\text { to top producing } 50 \%
\end{gathered}=4,2 \cdot 88 \%+4,4 \cdot 12 \%=4,2
$$

This score for iron $(4,2)$ is now multiplied by the percentage contribution of iron to the alloy $(73,56 \%)$. The sum of such multiplications (illustrated as the product of both dotted rectangles in Table 3 ) for all of the elements gives the score for the alloy $(3,7)$. 
Table 3 - Example calculation of the score for a concept. For the top producing countries of a given element, the percentage of global production for each of those countries is multiplied by indicator score for that country (the product of the two red dashed rectangles). These products are summed to give the 'Score for element'. The sum of the product of each score for an element with the percentage composition for that element (the product of both blue dotted rectangles) gives the 'Score for alloy'. (For the scores, a higher number means more equal income distribution.)

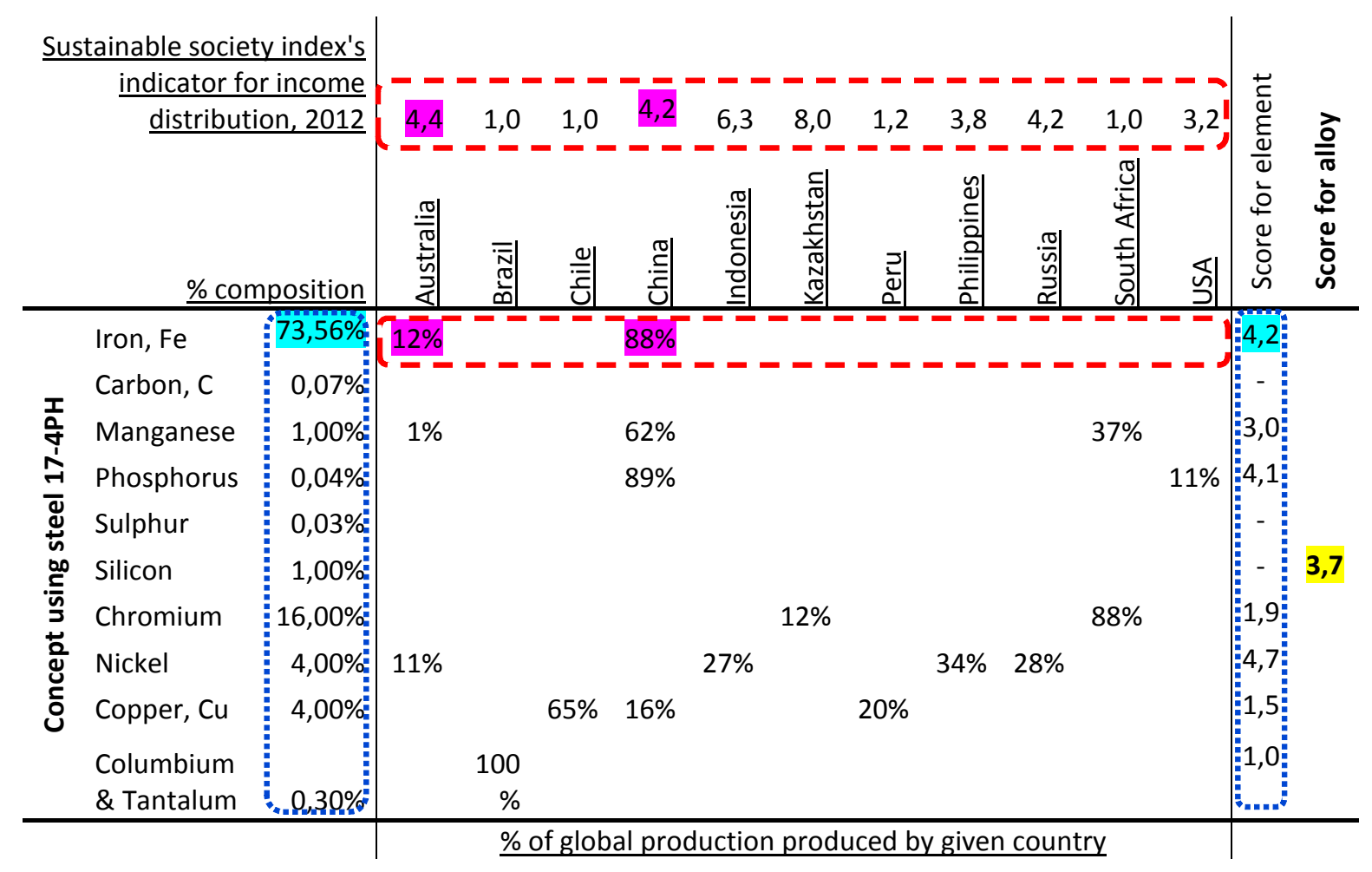

\subsection{ANALYSING THE CONCEPTS}

We tried each of the options shown in Table 1. Each option gives similar analysis results for the concepts, which is not surprising since the options vary only a little. According to the analysis, the extraction activities for concept $B$ have less social sustainability impacts than for concept A. However, concept $A$ extraction activities performed better according to some of the indicators. These results can be seen in Table 4, where the colour indicates which concept has extraction activities that are more socially sustainable than the other concept. Blue and yellow shading show where concept $B$ (blue) and concept A (yellow) have the highest score for a given indicator/principle for the material extraction activities. Grey shading shows where it is not possible to conclude which concept is better. 


\section{Option 1}

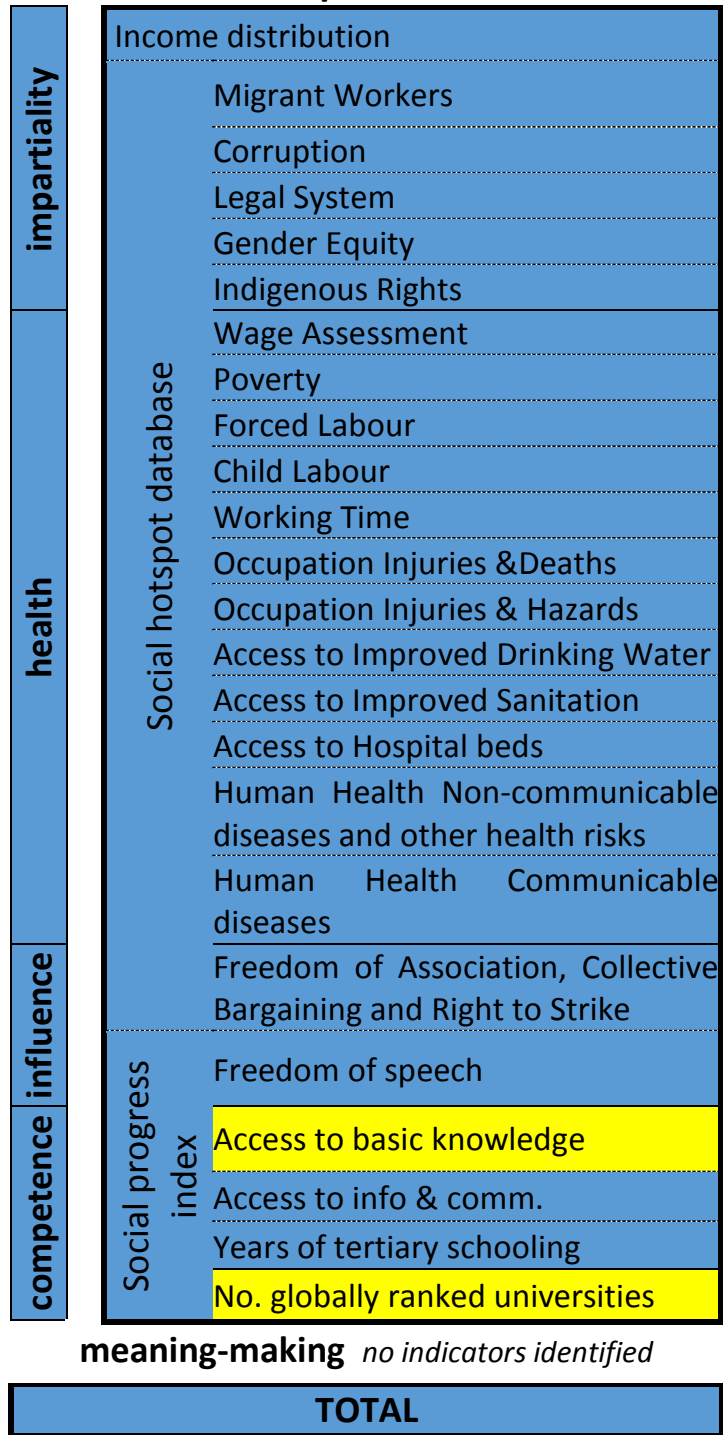

\section{Option 2}

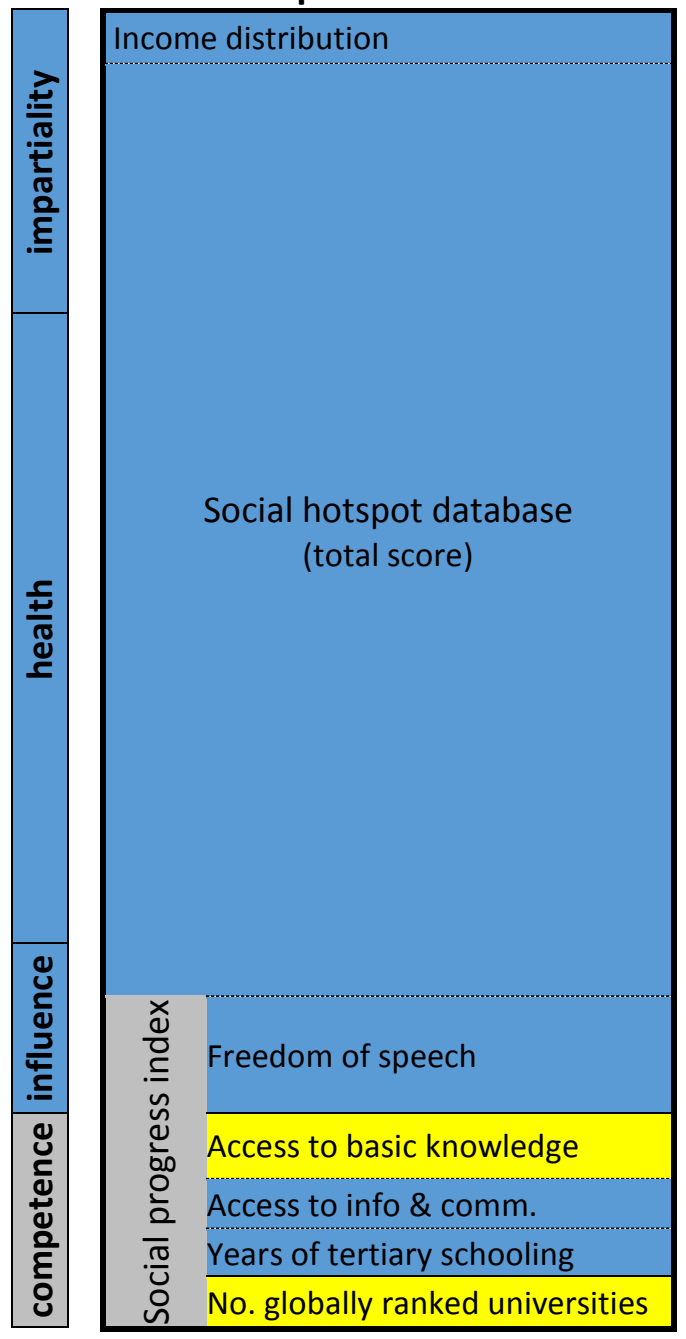

meaning-making no indicators identified TOTAL
Option 3

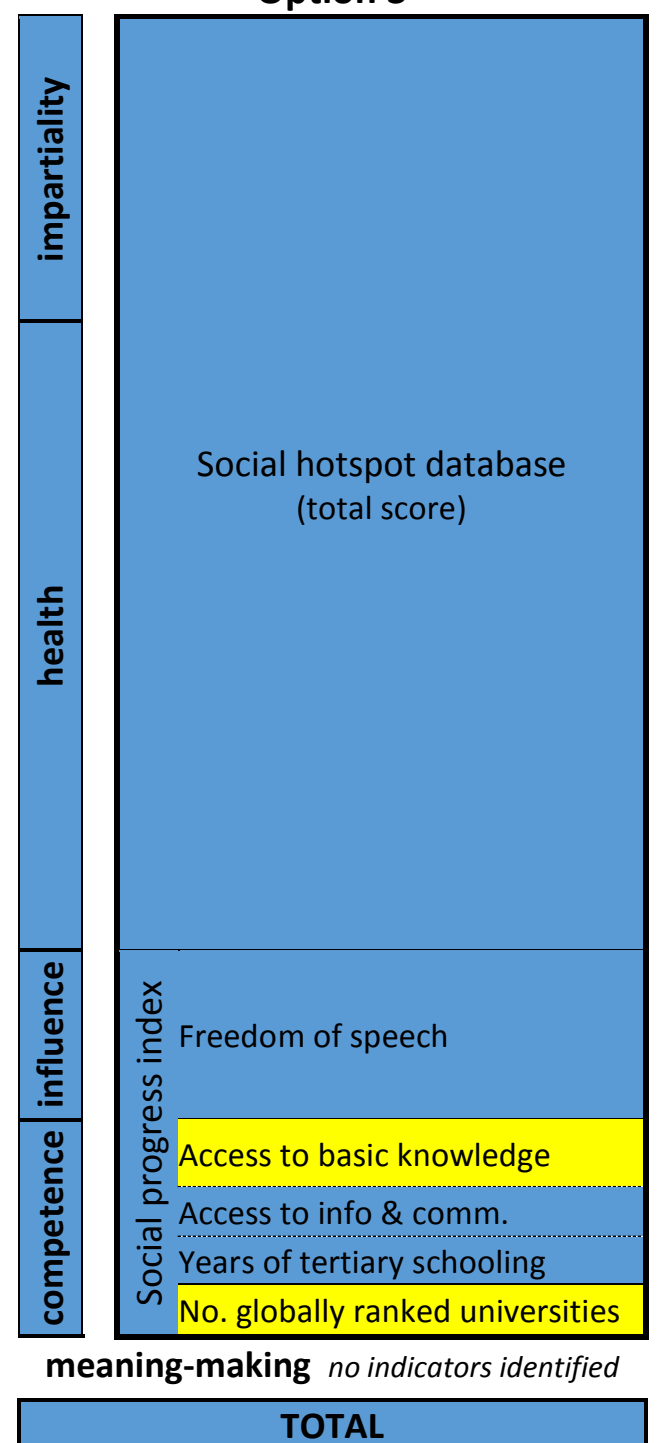




\section{EVALUATION RESULTS}

As we iterated the design of the prototype, evaluation of earlier prototypes was incorporated into design of the next version. In this section, we share the overall evaluation results.

Performing the analyses for options 2 and 3 was significantly easier than for option 1 since the second and third options required considerably less digging through the social hotspot database. Our experience was that the SHDB was challenging to use due to its default settings like reset time, number of countries and sectors that can be compared along with other technical details.

While using the indicators and performing the analyses, we started to recognise the inaccuracy or incomplete nature of many of them. Not only were we modelling the location, but also many indicators had data missing for one or two of the countries or presented data in a way that was difficult to accurately read.

In summary, although we identified three options for compiling the results from the indicators in order to compare concepts for the materials extraction phase, none of these options were ideal. All the indicators use incomplete and inaccurate data. Furthermore, we are only using the indicators to help us analyse the likely (not the actual) places of extraction.

When we shared our prototype with the first group (representatives of the case company), their project leader also brought up the concerns about gaining meaningful results from applying these approximations. When we shared our conclusions with the second group, they agreed with us. They also stated that it may be interesting to investigate how this approach might support procurement and supply chain management decision-making.

\section{DISCUSSION}

Our aim was to develop support for product developers in the case study company to use the newly developed social sustainability principles to analyse the extraction activities associated with two concept options. This seems an apt question to explore as organizations and product developers continue to ask for this kind of support. As a result of our iterative prototyping, we derived the approach outlined in section 3 . Through case study testing, we gained learnings from feedback and our experience. The learnings are:

- The approach enables analysis, but is not accurate enough analysis for selecting concepts.

This gives rise to the following questions:

1. Could the approach be useful for other decision-making?

2. Could this sort of support be useful if it can be turned into an instrument of learning?

The following subsections cover each of these points. 


\subsection{APPROACH ENABLES ANALYSIS, BUt NOT ACCURATE ENOUGH ANALYSIS FOR SELECTING CONCEPTS}

One aim was to make the support usable ${ }^{2}$ to the product developer on the ground. Our experience with the test case indicates that the developed support is indeed usable, at least enough to be considered for usability tests with product developers.

The bigger question is: Is the approach $u s e f u l^{3}$ for analysing product concepts as regards social sustainability. The straightforward answer is that it can be useful to identify potential contributions and social sustainability challenges in the probable countries involved, and therefore could be useful in the sense of raising awareness of these potential challenges. However, it is not particularly useful for comparing the extraction lifecycle phase for two specific product concepts that do not differ significantly in design.

The main challenge remains in that companies very often do not know where their material (those specific molecules) come from. For example, after being mined, the case company's raw materials are sent to be processed, potentially mixed with material from other sources, combined into an alloy, and sold on the open market before being used to create components. These multiple steps performed in multiple locations by multiple actors make traceability difficult, and the case company did not know where their molecules were extracted. Improved traceability could therefore be a potential enabler of better social sustainability analysis.

Given this situation we focused on ways to analyse the probability of contributing to un-sustainability. Of course, by its nature a model of reality is an approximation. Our support includes the following approximations:

- We created a probability model for the raw materials extraction countries. We used the countries that together form the top $50 \%$ of production for a material and weighted them. However, of course, in each instance of a material, the approximation provided by this model of extraction location might not be true.

- Since the location model gives the location in terms of country, we had to use social impact data (indicators) at the country level (or sector level within the country, when available) to give an approximation of the actual social impact. Of course, this representation is a gross generalization and possibly not every raw extraction company has these, often negative, social impacts. For example, an extraction company may not engage in child labour practices, despite being located in a country or sector where the risk of child labour is high. So, although creating a model does enable analysis, the granularity of the model does not allow us to know the actual child labour practices.

- The SHDB indicators are themselves approximations, which are created by aggregating data from multiple sources in the aim of assigning one number to set of inter-related and complex issues.

The approximations in our approach - modelling and use of indicators - enables analysis, but likely results in large cumulative errors due to performing multiple numerical operations on data that is quite a rough approximation. When we shared our prototype with representatives of the case

\footnotetext{
2 Usability describes "whether the support can be used for the task for which it is intended" (Blessing and Chakrabarti 2009; pg 37, 38).

${ }^{3}$ Usefulness describes the support's "ability to realise the expected impact" (Blessing and Chakrabarti 2009; pg 167).
} 
company, their project leader also brought up the concerns about gaining meaningful results from applying these approximations.

Our conclusion is that this approach enables analysis of extraction activities (is usable), but the analysis is not accurate enough to be useful for informing the current decision (between two closely related concepts). This gives rise to following two follow-up questions: (1.) Could this approach be considered elsewhere in the organisation's decision-making? (2.) Could this sort of support be useful for product developers if it can be turned into an instrument of learning rather than a tool that delivers answers?

\subsection{COULD THIS APPROACH BE USEFUL FOR OTHER DECISION-MAKING?}

In relation to (1.), a great challenge to manufacturing companies is that social impacts tend not to be related to the nature of a specific product or production process, but are rather dependent of the conduct of the company carrying out the process (Dreyer et al. 2006, Jørgensen 2013). Supply chains can be quite complex and often global, resulting in organizations struggling with the challenge of data availability. The unavailability or inaccuracy of data may mean that the only way to address social sustainability in the supply chain is to be proactive and try to influence it, rather than trying to measure and compare social impacts.

Proactively addressing social sustainability in the supply chain (and whole value chain) is, however, not just about selecting concepts. This is something that needs to be decided at a governance level of the organization and would be executed through cross-functional collaboration (Petala et al. 2010). In the future, researchers may wish to therefore focus on developing support for cross-functional teams to proactively address sustainability.

\subsection{COULD THIS SORT OF SUPPORT BE USEFUL IF IT CAN BE TURNED INTO AN INSTRUMENT OF LEARNING?}

Our conclusion does not mean that nothing should be done to help product developers selecting concepts. We do not want people to draw the conclusion that working with social sustainability principles is too difficult and translate that to 'we will do nothing' or 'cannot do anything about it'. We believe it is a good idea to create support for all activities. Questions about sustainability need to be asked in all parts of the organization and an impetus for change can originate from anywhere (Grayson et al. 2011). Therefore, we believe that it is important to still consider how to support product developers and address the second question - Could this sort of support be useful if it can be turned into an instrument of learning? The challenging nature of change is a barrier to eco-design implementation (Le Pochat et al. 2007) and therefore learningful support may be a critical enabler of eco-design and socially sustainable product development implementation.

So, while the prototype has its limitations, future work might involve investigating if it could be redesigned to help product developers to learn about social sustainability issues and gain insights into what can be done. Literature shows that (numerical) modelling enables an opportunity for insights into consequences (Keeney 1992) and that when making decisions in a complex (sustainability) context with multiple stakeholders, modelling can be helpful to provide insights, but not answers (Gregory et al. 2012). It seems that there is potential for using the support to be learningful in itself. Depending on when the product developers use the support, the learning during the decision-making may not have a great impact on the current particular product development project. But at least the people and the organisation can take the learning with them for future product development projects, contributing not only to individual, but also organizational learning. In fact, taking a product lifecycle perspective could help companies to visualise potential problems in their value chain that would not 
be seen when taking a supply chain management approach that addresses only first and possibly second tier suppliers. Any learning, however, requires that the decision-makers themselves use the support and not contract out the analysis.

If considering repurposing the support to be learningful, it is important to reconsider within the frame of wider decision support, not just the support for the analysis. Analysis is only one element that contributes to decision-making and product developers also need support in terms of a decisionmaking process. This is particularly important since the 'quality of process to exploit analysis and reach decision' can contribute 6 times greater to decision-making performance than the 'quantity and detail of analysis performed' (Lovallo and Sibony 2010). Thus, the design for learningful support should consider supporting the 'whole' decision-making process, and not just the analysis.

\subsection{REFLECTIONS ON OUR RESEARCH APPROACH}

Based on the expressed need from the case company, we assume that product developers want a (numerical) analysis that can be included in their trade-off decisions. However, not all product developers may want such an approach to analysis. When designing for user experience or customercentred experience, product developers are familiar with including intangibles in their concept development decision-making (for example, Hassenzahl and Tractinsky 2006) and so therefore may not want a numerical proxy. And numerical aggregation is not always recommended for decisionmaking in complexity (Gregory et al. 2012). Yet, as the request from the case company shows, numeric analysis is sometimes desired and an opportunity to try to find a way to support product developers who take a numerical analysis-centric approach to incorporating sustainability into their decisionmaking exists.

Our research approach was to prototype, the aim of which is to learn quickly and early (Kelley 2001). We therefore took a pragmatic attitude to find something that was good enough in order to try it out with the ultimate aim of learning by quickly completing at least one design-test cycle. This worked in our context and paid off especially given the result, but the prototypical nature of the approach that we share in this paper should be considered by anyone wishing to use or build on it.

We have performed the early steps of evaluation by testing our ideas with ourselves (the researchers) taking on the role of product developers involved in the decision-making rather than involving actual product developers and by getting feedback from case company representatives. This seemed appropriate given the level of realisation of the support (Blessing and Chakrabarti 2009) and the desire for learning quickly and early. From our experience of taking on this role, we concluded that the prototype approach was usable. Once the learnings from this evaluation have been incorporated and the support redesigned, it could also be tried out with 'real' product developers as the users.

\subsection{CONCLUSION AND FUTURE RESEARCH}

We designed a first prototype of support for using social sustainability principles to analyse the extraction lifecycle activities associated with two product concepts. This support instructs users to take a modelling approach, using existing databases and indicators selected due to their relevance to scientific principles for social sustainability. We then performed initial evaluation of the support, through which we learnt that the approach may make it possible for product developers to analyse extraction activities, but the level of accuracy of analysis that is possible is not good enough for comparing the concepts in the case study decision. Studies are now needed to investigate (1.) how this approach could be made useful for supporting other decision-making, including providing cross- 
functional support; and (2.) how the approach can be developed or re-designed to be learningful for the product developers by raising awareness of potential contributions to unsustainability.

Implications for the case company, and wider industry, are to recognise (a) the imperfections with analysing early lifecycle activities with respect to social sustainability and (b) that mitigating the risk of an unsustainable supply chain is unlikely to occur through selecting concepts based on their 'social sustainability score', but rather requires actively seeking to improve social conditions in the supply chain.

Implications for the research community are to conduct future research on how to design support for product developers to integrate social sustainability considerations in concept selection decisionmaking such that the support is learningful for the users. This future research may include investigating how to design learningful support that includes encouraging (i) the whole process of decision-making, not just the analysis, (ii) bigger-picture thinking about how to proactively address issues, and (iii) an integrated approach to sustainable supply chain management and product development.

\section{ACKNOWLEDGMENTS}

We thank our project partner, GKN Aerospace, for providing the context that raised our question, for providing the description of the lifecycle activities for their two concepts and feedback. We are also grateful to our colleagues, Cecilia Bratt, Pia Lindahl, Sophie Hallstedt, Marco Bertoni and Göran Broman, for their sharp feedback on our writing. In addition, we gratefully acknowledge financial support from the Swedish Knowledge and Competence Development Foundation (Stiftelsen för kunskaps- och kompetensutveckling) for the Model Driven Development and Decision-Support project and the FUTURA foundation.

\section{REFERENCES}

Benoit, Catherine, Gregory A. Norris, Sonia Valdivia, Andreas Ciroth, Asa Moberg, Ulrike Bos, Siddharth Prakash, Cassia Ugaya, and Tabea Beck. "The guidelines for social life cycle assessment of products: just in time!" The international journal of life cycle assessment 15, no. 2 (2010): 156163.

Bertoni, Marco, Sophie Hallstedt, and Ola Isaksson. "Value assessment of sustainability hotspots in conceptual design: an aerospace study." In International Symposium on Tools and Methods of Competitive Engineering (TMCE). 2014.

Bhamra, T., S. Evans, Timothy Charles McAloone, M. Simon, S. Poole, and A. Sweatman. "Integrating Environmental Decisions into the Product Development Process: Part 1 - The Early Stages." Proceedings of the First International Symposium on Environmentally Conscious Design and Inverse Manufacturing (ISBN: 0-7695-0007-2), pages: 329-333, 1999.

Blessing, Lucienne TM, and Amaresh Chakrabarti. DRM, a design research methodology. Springer Science \& Business Media, 2009.

British Geological Survey. Risk List 2012. PDF available at: http://www.bgs.ac.uk/downloads/start.cfm?id=2643. 
Byggeth, Sophie, Göran Broman, and Karl-Henrik Robèrt. "A method for sustainable product development based on a modular system of guiding questions." Journal of Cleaner Production 15, no. 1 (2007): 1-11.

Broman, Göran Ingvar, and Karl-Henrik Robèrt. "A framework for strategic sustainable development." Journal of Cleaner Production (this issue).

Cuthill, Michael. "Strengthening the 'social' in sustainable development: Developing a conceptual framework for social sustainability in a rapid urban growth region in Australia." Sustainable Development 18, no. 6 (2010): 362-373.

Dempsey, Nicola, Glen Bramley, Sinéad Power, and Caroline Brown. "The social dimension of sustainable development: Defining urban social sustainability." Sustainable Development 19, no. 5 (2011): 289-300.

Dreyer, Louise, Michael Hauschild, and Jens Schierbeck. "A framework for social life cycle impact assessment (10 pp)." The International Journal of Life Cycle Assessment 11, no. 2 (2006): 88-97.

Dreyer, M., C. Mays, P. Sellke, O. Renn, R. Kuhn, R. Schröter, M. Hausschild et al. "Literature Review on Social Indicators and Integrated Model of Indicator Selection." Available online: http://www. prosuite. org/c/document_library/get_file. 2010.

Good country index. http://www.goodcountry.org/. Accessed July 2014.

Gmelin, Harald, and Stefan Seuring. "Determinants of a sustainable new product development." Journal of Cleaner Production 69 (2014): 1-9.

Grayson, David, Melody McLaren, and Heiko Spitzeck. "Social Intrapreneurs - An Extra Force for Sustainability." A Doughty Centre for Corporate Responsibility Occasional Paper. 2011.

Gregory, Robin, Lee Failing, Michael Harstone, Graham Long, Tim McDaniels, and Dan Ohlson. Structured decision making: a practical guide to environmental management choices. John Wiley \& Sons, 2012.

Hallstedt, Sophie I. "Sustainability criteria and sustainability compliance index for decision support in product development." Journal of Cleaner Production (this issue). doi:10.1016/j.jclepro.2015.06.068

Hallstedt, Sophie, and Ola Isaksson. "Clarification of sustainability consequences of manufacturing processes in conceptual design." In DS 75-9: Proceedings of the 19th International Conference on Engineering Design (ICED13), Design for Harmonies, Vol. 9: Design Methods and Tools, Seoul, Korea, 19-22.08. 2013. 2013.

Hassenzahl, Marc, and Noam Tractinsky. "User experience-a research agenda." Behaviour \& information technology 25, no. 2 (2006): 91-97.

Jørgensen, Andreas, Agathe Le Bocq, Liudmila Nazarkina, and Michael Hauschild. "Methodologies for social life cycle assessment." The international journal of life cycle assessment 13, no. 2 (2008): 96-103.

Jørgensen, Andreas. "Social LCA-a way ahead?" The International Journal of Life Cycle Assessment 18, no. 2 (2013): 296-299.

Keeney, Ralph L. Value-focused thinking: A path to creative decision-making. Harvard University Press, 1992.

Kelley, Tom. "Prototyping is the shorthand of innovation." Design Management Journal (Former Series) 12, no. 3 (2001): 35-42. 
Krishnan, Viswanathan, and Karl T. Ulrich. "Product development decisions: A review of the literature." Management science 47, no. 1 (2001): 1-21.

Kunz, Jan. "Social sustainability and community involvement in urban planning." University of Tampere, Finland (2006): 951-44.

Le Pochat, Stéphane, Gwenola Bertoluci, and Daniel Froelich. "Integrating ecodesign by conducting changes in SMEs." Journal of Cleaner Production 15, no. 7 (2007): 671-680.

Littig, Beate, and Erich Griessler. "Social sustainability: a catchword between political pragmatism and social theory." International Journal of Sustainable Development 8, no. 1 (2005): 65-79.

Lovallo, Dan, and Olivier Sibony. "The case for behavioral strategy." McKinsey Quarterly 2 (2010): 3043.

Minerals UK, Centre for sustainable mineral development. World Mineral Statistics. http://www.bgs.ac.uk/mineralsuk/statistics/wms.cfc?method=searchWMS. Accessed July 2014.

Missimer, Merlina. "Social Sustainability within the Framework for Strategic Sustainable Development." PhD Dissertation, Blekinge Institute of Technology. (2015).

Missimer, Merlina, Karl-Henrik Robèrt, and Göran Broman. "Lessons from the field: A first evaluation of working with the elaborated social dimension of the Framework for Strategic Sustainable Development." Presented at Relating Systems Thinking and Design 3. Oslo, 15 - 17 October 2014.

Missimer, Merlina, Karl-Henrik Robèrt, and Göran Broman. "A Strategic Approach to Social Sustainability - Part 1: Exploring the Social System". (this issue a).

Missimer, Merlina, Karl-Henrik Robèrt, and Göran Broman. "A Strategic Approach to Social Sustainability - Part 2: A Principle-based Definition.".(this issue b).

Norris, Catherine Benoît, Gregory A. Norris, and Deana Aulisio. "Efficient Assessment of Social Hotspots in the Supply Chains of 100 Product Categories Using the Social Hotspots Database." Sustainability 6, no. 10 (2014): 6973-6984.

Ny, Henrik, Jamie P. MacDonald, Göran Broman, Ryoichi Yamamoto, and Karl-Henrik Robèrt. "Sustainability constraints as system boundaries: an approach to making life - cycle management strategic." Journal of Industrial Ecology 10, no. 1 - 2 (2006): 61-77.

Omann, Ines, and Joachim H. Spangenberg. "Assessing social sustainability." In Biennial Conference of the International Society for Environmental Economics, vol. 7. 2002. Available at http://seri.at/wp-content/uploads/2010/05/Assessing_social_sustainability.pdf (Accessed November 29th, 2012)

Partridge, Emma. "Social sustainability': a useful theoretical framework." In Australasian political science association annual conference, pp. 28-30. 2005.

Petala, Effrosyni, Renee Wever, Chris Dutilh, and Han Brezet. "The role of new product development briefs in implementing sustainability: A case study." Journal of Engineering and Technology Management 27, no. 3 (2010): 172-182.

Savin-Baden, Maggi, and Claire Howell Major. Qualitative research: The essential guide to theory and practice. Routledge, 2013.

Social Hotspots Database. Available online: http://www.socialhotspot.org/content/publication. Accessed August 2014.

Social progress imperative. Social progress index 2014.

http://www.socialprogressimperative.org/data/spi. Accessed July 2014 
Sustainable society index. 2012. http://www.ssfindex.com/. Accessed July 2014.

Thompson, Anthony, Pia Lindahl, Sophie Hallstedt, Henrik Ny, and Göran Broman. "Decision support tools for sustainability in product innovation in a few Swedish companies." International Conference on Research into Design (ICoRD). Research Publishing, 2011.

Ullman, David G. The mechanical design process. McGraw. Third edition, 2003.

Ulrich, Karl T. and Steven Eppinger. Product design and development. McGraw-Hill. Fifth edition, 2012. ISBN 9780071086950.

UNDP. Inequality adjusted human development index. United Nations Development Programme. http://hdr.undp.org/en/content/table-3-inequality-adjusted-human-development-index. Accessed July 2014.

Vallance, Suzanne, Harvey C. Perkins, and Jennifer E. Dixon. "What is social sustainability? A clarification of concepts." Geoforum 42, no. 3 (2011): 342-348.

Weingaertner, Carina, and Åsa Moberg. "Exploring social sustainability: learning from perspectives on urban development and companies and products." Sustainable Development 22, no. 2 (2014): 122-133. DOI: $10.1002 /$ sd.536.

World Bank. Worldwide governance indicators. http://info.worldbank.org/governance/wgi/index.aspx\#home. Accessed July 2014.

Wu, Ruqun, Dan Yang, and Jiquan Chen. "Social life cycle assessment revisited." Sustainability 6, no. 7 (2014): 4200-4226.

Yin, Robert K. Case study research: Design and methods. Thousand Oaks. Fourth edition, 2009. 